\title{
Laser-induced prenucleation of alumina for electroless plating
}

\author{
P.B. Shrivastva ${ }^{\text {a,1 }}$, C. Harteveld ${ }^{\text {b }}$, C.A. Boose ${ }^{a}$ and B.H. Kolster ${ }^{\text {a }}$ \\ a Foundation for Advanced Metals Science (SGM), P.O. Box 8039, 7550 KA Hengelo, Netherlands \\ ${ }^{b}$ Department of Physics, University of Twente, Enschede, Netherlands
}

Received 4 March 1991; accepted for publication 12 May 1991

\begin{abstract}
This paper deals with the deposition of palladium from decomposition of a thin palladium acetate layer on rough and porous alumina ceramic surfaces by irradiating it with a UV excimer laser. The palladium acetate layer was formed from a combination of propyl glycol methyl ether acetate solvent and photoresist, and the undecomposed material was removed with the photoresist remover. The discontinuous palladium cluster film formed by the technique was used as seed for electroless coatings. Different patterns were obtained using point focus as well as projection patterning method and subsequently plated with adhesive layers of electroless $\mathrm{Ni}-\mathrm{B}$ coatings.
\end{abstract}

\section{Introduction}

The use of a laser for direct deposition of metals on conducting and non-conducting surfaces has been the subject of much attention in recent days [1,2]. Attempts have been made to deposit metal from gas phase [3-5], liquid phase [6-11] and thin metallo-organic films [12-20]. The deposition from solid state metallo-organic film offers the advantage of increased safety and ease of handling. Moreover, such films can be formed on surfaces from spin, spray or dip coatings and can be decomposed in air at lower temperatures $\left(200-300^{\circ} \mathrm{C}\right)$. In the literature, most of the work deals with the decomposition of metallo-organics on quartz or silicon substrates; little information is available on ceramic substrates, which is an interesting subject to be investigated.

This paper reports the results of deposition of palladium from a palladium acetate film formed from a combination of propyl glycol methyl ether acetate and photoresist. The palladium-containing metallo-organic film was formed on rough and porous commercial ceramic and irradiated with a

${ }^{1}$ On study leave for post-doc from Bhabha Atomic Research Centre, Bombay, India.
UV excimer laser. This combination was studied since the palladium acetate-chloroform system as reported by Gross et al. [17] was not suitable for the studied substrates as we could not remove unwanted palladium acetate after irradiation, leading to plating of electroless nickel all over the substrate surface.

\section{Experimental}

A xenon chloride excimer laser (Lambda Physik, Model LPX 100) producing 25 ns pulses at 309 $\mu \mathrm{m}$ was used in the study. The laser beam was focussed at the substrate surface with a rectangular slit of size $18 \times 5 \mathrm{~mm}$ and with a cylindrical lense having a focal length of $550 \mathrm{~mm}$.

The substrates used were commercial alumina plates of $50 \times 50 \times 0.6 \mathrm{~mm}$, having a purity of $96.0 \%$ to $99.5 \%$. Without any special cleaning or pretreatment of the alumina ceramic, the palladium acetate films were spin- and dip-coated from a solution of $1 \mathrm{~g}$ palladium acetate dissolved in $100 \mathrm{ml}$ of propyl glycol methyl ether and $4 \mathrm{~g}$ of photoresist (Photoposit SP-20 ${ }^{\# 1}$ ). The coating was

\#1 Supplied by M/S Shipley Europe Ltd., England. 
dried in an oven at $70-80^{\circ} \mathrm{C}$ for $1 \mathrm{~h}$ and then irradiated with the laser. The unexposed material was removed by washing in a solution of photoresist remover (Photoposit remover $1112 \mathrm{~A}^{\# 1}$ ).

The deposited layer of palladium was plated with $\mathrm{Ni}-\mathrm{B}$ coating from an electroless $\mathrm{Ni}-\mathrm{B}$ bath containing $0.15 \mathrm{M}$ nickel chloride, $0.4 \mathrm{M}$ glycolic acid, $0.3 \mathrm{M}$ lactic acid, and $0.05 \mathrm{M}$ dimethylamine borane. The bath was operated at an $\mathrm{pH}$ of 6.0 and at a temperature of $65^{\circ} \mathrm{C}$ for $1 \mathrm{~h}$. The thickness of the palladium acetate layer on the ceramic was measured by a Dektak surface profilometer (Dektak 3030) with a stylus of $12.5 \mu \mathrm{m}$ radius. Energy dispersive X-ray analysis (EDAX) and scanning electron microscope (SEM) were used to investigate the palladium layer obtained after laser irradiation. The adhesion of the coating obtained after electroless plating was measured by the "tape peel off" test.

\section{Results and discussion}

The alumina ceramic substrates with a thin layer of palladium acetate obtained by spin and dip coatings were initially irradiated in the focal point of the optical system having beam size of $0.4 \times 0.1 \mathrm{~mm}$. The laser beam was set at varying energies $(10-50 \mathrm{~mJ} /$ pulse) and repetition rates $(20-100 \mathrm{~Hz})$. Adhering layers of palladium were obtained, when irradiated for $30-50$ pulses, at energies of $15-20 \mathrm{~mJ} /$ pulse $\left(1-2 \mathrm{~mJ} / \mathrm{mm}^{2}\right)$ and at frequencies of $80-100 \mathrm{~Hz}$. Good adhesion was obtainable in the samples having a palladium acetate layer of less than $1 \mu \mathrm{m}$, where the laser light penetrates sufficiently through the film, to the film/substrate interface. Samples having more than $1 \mu \mathrm{m}$ thickness resulted in palladium layers which were washed away while cleaning the unexposed surfaces.

The results of the examination by EDAX and SEM are presented in figs. 1 and 2. The presence of palladium on the irradiated spot, seen by EDAX measurement is shown in fig. 1. The EDAX studies have confirmed that the deposited material is indeed palladium and has no detectable impurity. The SEM pictures of the ceramic surface before and after laser irradiation showing the mor-

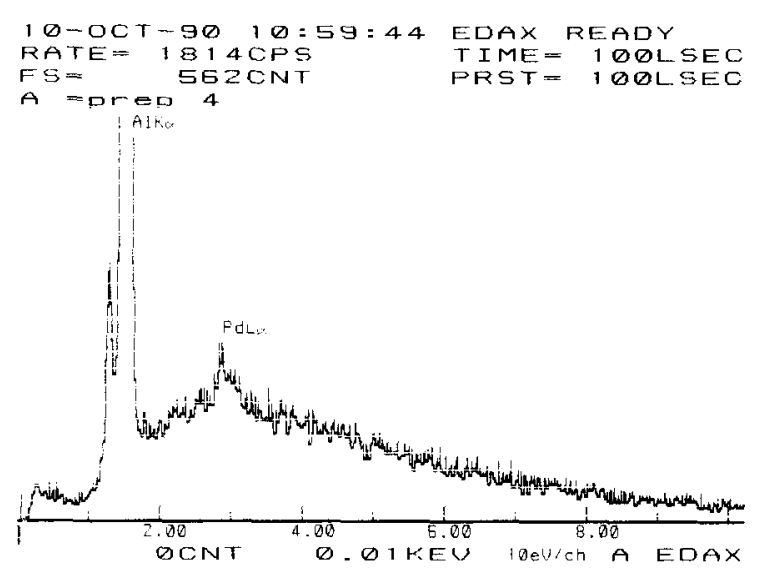

Fig. 1. Energy dispersive X-ray analysis of a palladium layer on alumina after laser irradiation.
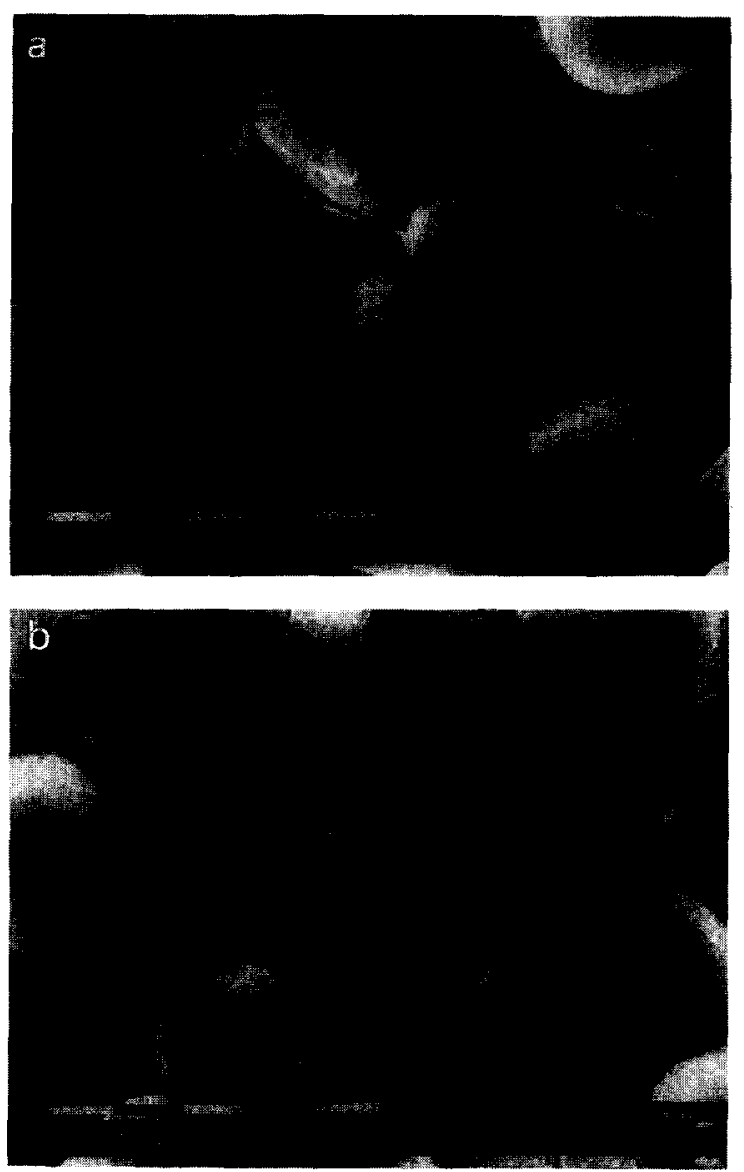

Fig. 2. Scanning electron micrographs of alumina ceramic before and after laser irradiation: (a) before laser irradiation, (b) after laser irradiation. 


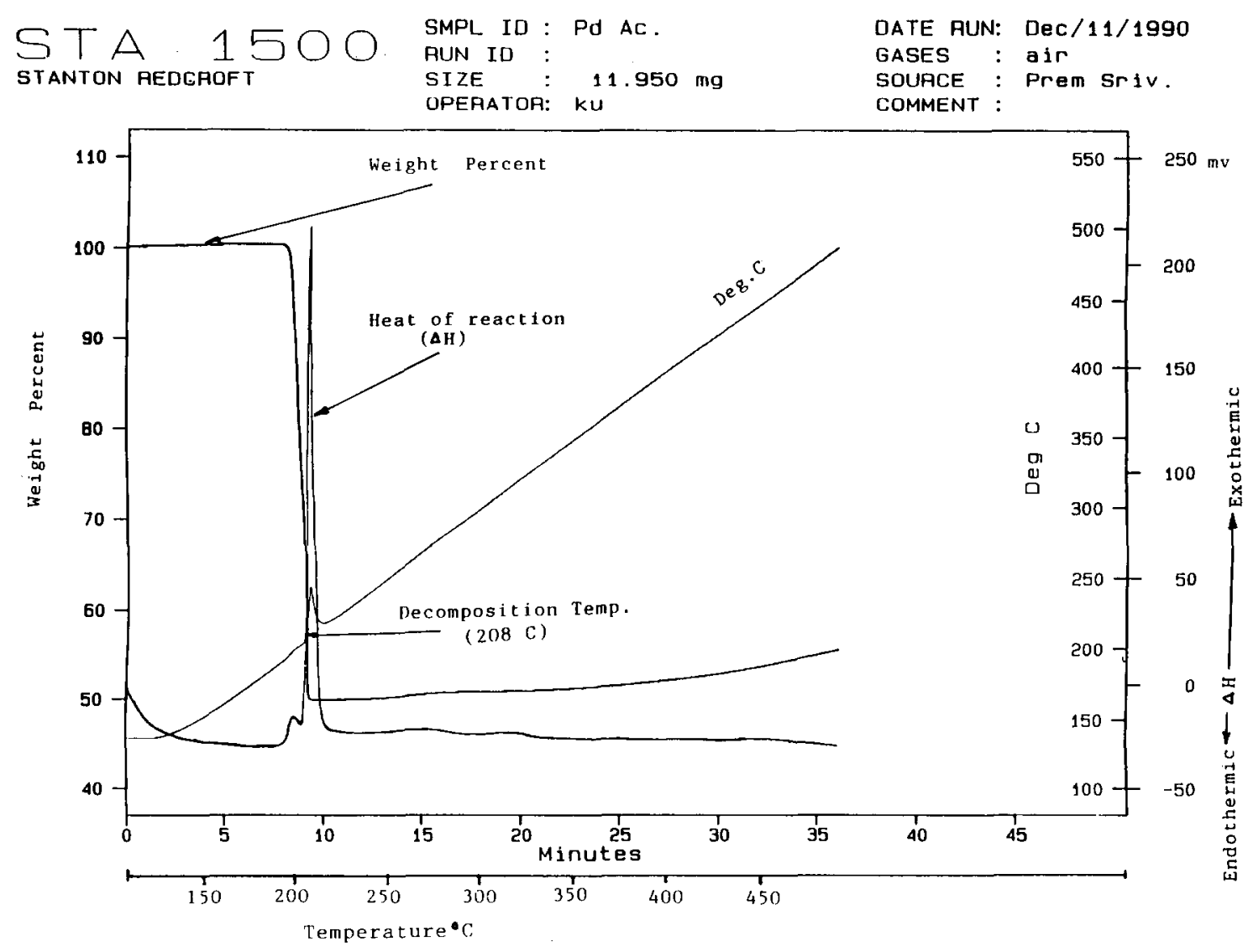

Fig. 3. Differential thermal analysis and thermal gravimetric analysis of palladium acetate.

phology of the deposited palladium are presented in fig. 2 . It can be seen from fig. 2 that palladium is being deposited as a discontinuous film on the grains of the ceramic. These particles of palladium are favourable for electroless plating since they are more catalytically active than continuous palladium deposits [21]. A possible reason for the formation of discontinuous clusters could be the exothermic reaction of palladium acetate at its decomposition temperature, as can be seen from the measurement of differential thermal analysis (fig. 3). The decomposition of palladium acetate, as measured by the thermal gravimetric analysis, was found to be incomplete (about 50\%) in the temperature range of $208-400^{\circ} \mathrm{C}$ (fig. 3). The remaining undecomposed palladium acetate was removed from the surface by photoresist remover.

Following the encouraging results with the strongly focussed laser beam, different patterns of palladium layers were produced using the projection patterning technique. Fig. 4 shows the photomicrograph of the patterns drawn by this technique. As can be seen, a sharp edge without any palladium particles in the surrounding areas was achieved, which is normally not attainable by the use of an argon laser [17]. The irradiated lines thus obtained were subsequently plated with electroless $\mathrm{Ni}-\mathrm{B}$ coatings to a thickness of $3 \mu \mathrm{m}$. The ad- 

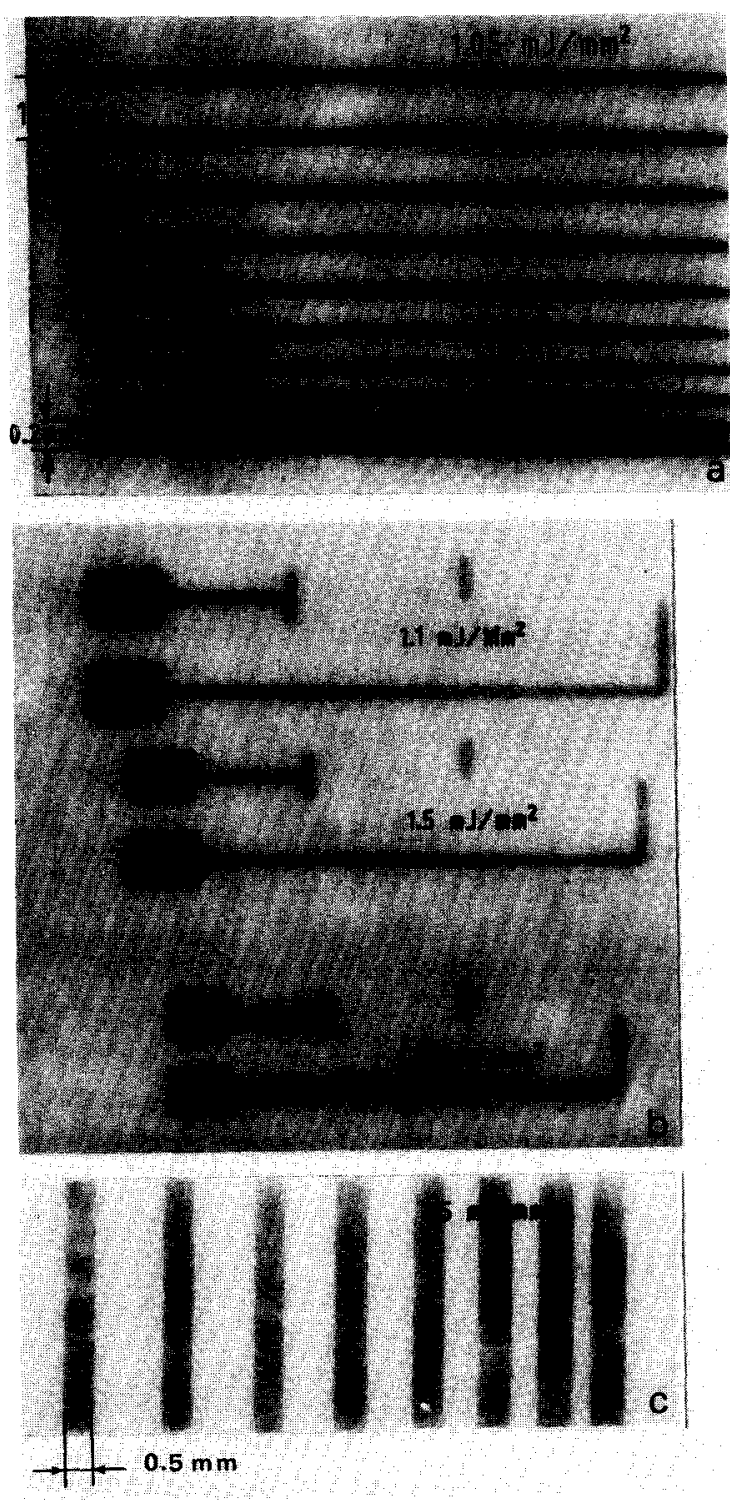

Fig. 4. Photomicrographs of palladium layer pattern on alumina ceramic after laser irradiation: (a) Line pattern drawn at scan rate of $300-400 \mu \mathrm{m} / \mathrm{s}$. The single lines are each $0.25 \mathrm{~mm}$ wide with line-to-line spacing of 0.20 to $1.0 \mathrm{~mm}$. (b) Pattern obtained at laser power densities of $1.1,1.5$ and $1.95 \mathrm{~mJ} / \mathrm{mm}^{2}$. (c) Pattern obtained at laser power density of $1.5 \mathrm{~mJ} / \mathrm{mm}^{2}$ having lines of $0.50 \mathrm{~mm}$ width.

hesion of these coatings measured by the "tape peel off" method passed the test showing good adhesion of the coatings.

\section{Conclusions}

Alumina ceramic was prenucleated with palladium by a laser from a thin solid layer of palladium acetate formed from a combination of propyl glycol methyl ether acetate and photoresist. The discontinuous palladium cluster film formed on the alumina surface was used as seed for electroless plating. Different patterns were obtained by using a point focus and the projection patterning method. Lines with a sharp edge without any palladium particles in the surrounding area were achieved. Since palladium acetate decomposes at lower temperature $\left(208^{\circ} \mathrm{C}\right)$, the method can be successfully used for prenucleating other non-conducting materials.

Work is in progress to achieve similar patterns on anodized aluminium for use in the electronic industry.

\section{Acknowledgements}

The authors would like to thank J. Jansen, H.A.G.M. van Wolferen and K. Kumar for their help in the measurements. Thanks are also due to the Dutch Government for the financial support (IOP Metalen project Nr. C88, 414, SMXX).

\section{References}

[1] D. Bäuerle, Chemical Processing with Lasers, Vol. 1 of Springer Series on Material Science (Springer, Berlin, 1986).

[2] D. Bäuerle, Appl. Phys. B 46 (1988) 261.

[3] D.J. Ehrlich and J.Y. Tsao, J. Vac. Sci. Technol. B 1 (1983) 969.

[4] O. Gottsleben and M. Stuke, Appl. Phys. Lett. 52 (1988) 2230.

[5] B. Markwalder, M. Widmer, D. Braichotte and H. van den Bergh, J. Appl. Phys. 65 (1989) 2470.

[6] R.F. Karlicek, V.M. Donnelly and G.I. Collins, J. Appl. Phys. 53 (1982) 1084.

[7] H.R. Khan, M.U. Kittel and Ch.J. Raub, Plating Surf. Finish. 75 (1988) 58.

[8] R.J. von Gutfeld, M.H. Gelchinski, L.T. Romankiw and D.R. Vigliotti, Appl. Phys. Lett. 43 (1983) 876.

[9] C. Bocking, Trans. Inst. Met. Finish. 66 (1988) 50.

[10] J. Zahavi, S. Tamir, M. Rotel, G.J. Campisi, M. Halliwell and P.E. Pehrsson, in: Proc. 12th World Congr. on Surface 
Finishing, Interfinish Paris: Association Francaise des Ingenieurs et Techniciens de l'Electrolyse et des Traitements de Surface, October 1988, pp. 329.

[11] P.B. Shrivastva, C.A. Boose, B.H. Kolster, C. Harteveld and B. Meinders, Surf. Coat. Technol. 46 (1991) 131.

[12] C.M. Harish, V. Kumar and A. Prabhakar, J. Electrochem. Soc. 135 (1988) 2903.

[13] A. Gupta and R. Jagannathan, Appl. Phys. Lett. 51 (1987) 2254.

[14] R.C. Sausa, A. Gupta and J.R. White, J. Electrochem. Soc. 134 (1987) 2707.

[15] H. Esrom and G. Wahl, Chemtronics 4 (1989) 216.
[16] M.E. Gross, G.J. Fisanick, P.K. Gallagher, K.J. Schnoes and M.D. Fennell, Appl. Phys. Lett. 47 (1985) 923.

[17] M.E. Gross, A. Appelbaum and P.K. Gallagher, J. Appl. Phys. 61 (1987) 1628.

[18] P. Hoffmann, B. Lecohier, S. Goldoni and H. van den Bergh, Appl. Surf. Sci. 43 (1989) 54

[19] C.J. Chen, Appl. Phys. Lett. 56 (1990) 2411.

[20] A. Gupta and C.J. Chen, Appl. Phys. Lett. 56 (1990) 2516.

[21] M. Paunovic, in: Electroless Deposition of Metals and Alloys, Vol. 88-12 of the Proceedings of the Electrochemical Society, Eds. M. Paunovic and I. Ohino (Electrochemical Society, Pennington, NJ, 1988). 